Burge Angela (Orcid ID: 0000-0001-5455-6467)

Holland Anne (Orcid ID: 0000-0003-2061-845X)

McDonald Christine (Orcid ID: 0000-0001-6481-3391)

Abramson Michael (Orcid ID: 0000-0002-9954-0538)

Lahham Aroub (Orcid ID: 0000-0003-2090-0746)

Editorial Office Notes:

RES-18-956.R2

ORIGINAL ARTICLE

Received 3 December 2018

Invited to revise 5 February and 6 May 2019

Revised 8 April and 3 June 2019

Accepted 16 July 2019

Associate Editor: Melissa Benton

Senior Editor: Fanny Ko

Publication fee waiver: NO

Volume: 24

This is the author manuscript accepted for publication and has undergone full peer review but has not been through the copyediting, typesetting, pagination and proofreading process, which may lead to differences between this version and the Version of Record. Please cite this article as doi: $10.1111 /$ resp.13667

This article is protected by copyright. All rights reserved. 


\title{
Home-based pulmonary rehabilitation for COPD using minimal resources: an economic analysis
}

\author{
Angela T Burge, MPhysio \\ Discipline of Physiotherapy, La Trobe University, Melbourne, Victoria, Australia \\ Department of Physiotherapy, Alfred Health, Melbourne, Victoria, Australia \\ Institute for Breathing and Sleep, Melbourne, Victoria, Australia
}

Anne E Holland, PhD

Discipline of Physiotherapy, La Trobe University, Melbourne, Victoria, Australia Department of Physiotherapy, Alfred Health, Melbourne, Victoria, Australia Institute for Breathing and Sleep, Melbourne, Victoria, Australia

Christine F McDonald, PhD

Institute for Breathing and Sleep, Melbourne, Victoria, Australia

Department of Respiratory and Sleep Medicine, Austin Health, Melbourne, Victoria, Australia

Department of Medicine, The University of Melbourne, Melbourne, Victoria, Australia

Michael J Abramson, PhD

Department of Epidemiology \& Preventive Medicine, Monash University, Melbourne, Victoria, Australia

This article is protected by copyright. All rights reserved. 
Catherine J Hill, PhD

Institute for Breathing and Sleep, Melbourne, Victoria, Australia

Department of Physiotherapy, Austin Health, Melbourne, Victoria, Australia

\author{
Annemarie L Lee, $\mathrm{PhD}$ \\ Discipline of Physiotherapy, La Trobe University, Melbourne, Victoria, Australia \\ Department of Physiotherapy, Alfred Health, Melbourne, Victoria, Australia \\ Institute for Breathing and Sleep, Melbourne, Victoria, Australia
}

\author{
Narelle S Cox, PhD \\ Discipline of Physiotherapy, La Trobe University, Melbourne, Victoria, Australia \\ Institute for Breathing and Sleep, Melbourne, Victoria, Australia
}

Rosemary Moore, MPhysio

Institute for Breathing and Sleep, Melbourne, Victoria, Australia

\title{
Caroline Nicolson, MPhysio
}

Discipline of Physiotherapy, La Trobe University, Melbourne, Victoria, Australia Department of Physiotherapy, Alfred Health, Melbourne, Victoria, Australia

Paul O'Halloran, PhD

This article is protected by copyright. All rights reserved. 
Department of Public Health, La Trobe University, Melbourne, Victoria, Australia

Aroub Lahham, BSci (Physiotherapy)

Discipline of Physiotherapy, La Trobe University, Melbourne, Victoria, Australia Institute for Breathing and Sleep, Melbourne, Victoria, Australia

Rebecca Gillies, GDip (Exercise Physiology)

Discipline of Physiotherapy, La Trobe University, Melbourne, Victoria, Australia Department of Physiotherapy, Austin Health, Melbourne, Victoria, Australia

\begin{abstract}
Ajay Mahal, PhD
The Nossal Institute for Global Health, The University of Melbourne, Melbourne, Victoria, Australia
\end{abstract}

\title{
Correspondence:
}

Angela T Burge

Mailing address: Physiotherapy Department, The Alfred PO Box 315

Prahran VIC 3181 AUSTRALIA

Email: $\quad$ a.burge@alfred.org.au

\section{Summary at a glance:}

This article is protected by copyright. All rights reserved. 
This economic evaluation compared a new home-based pulmonary rehabilitation model with traditional centre-based practice, demonstrating favourable results using both costutility and cost-effectiveness approaches. Regardless of programme location, completion of pulmonary rehabilitation was associated with a significant reduction in health care costs in the following 12 months.

This article is protected by copyright. All rights reserved. 


\section{Author contribution roles using the CRediT Taxonomy}

Please complete this Table on behalf of and with approval of all authors

-Note that not all categories are relevant to each type of research $\rightarrow$ Only select those contribution roles that are relevant to your study.

-This information will be translated into an 'Author contribution statement' by the typesetters and included at the end of your publication $\rightarrow$ The corresponding author is responsible for checking the 'Author contribution statement' against the completed table below in the final version of the manuscript.

- DO NOT FORGET: If not done yet, you will ALSO be required to complete the same Author contribution information for all authors in ScholarOne at Step 4 of the First Look finalization.

\begin{tabular}{|c|c|c|}
\hline Role & Degree & Author initials (reflecting the full author name on the manuscript) \\
\hline \multirow{3}{*}{1 -Conceptualization } & Lead & AEH \\
\hline & Equal & CFM, AM \\
\hline & Supporting & PO \\
\hline \multirow{3}{*}{2 - Data curation } & Lead & ATB \\
\hline & Equal & AEH \\
\hline & Supporting & NSC \\
\hline \multirow{3}{*}{3 -Formal analysis } & Lead & ATB \\
\hline & Equal & AEH, MJA, AM \\
\hline & Supporting & CFM \\
\hline \multirow{3}{*}{4 - Funding acquisition } & Lead & AEH \\
\hline & Equal & CFM, AM \\
\hline & Supporting & $\mathrm{PO}$ \\
\hline \multirow{3}{*}{5 - Investigation } & Lead & ATB \\
\hline & Equal & NSC \\
\hline & Supporting & AEH, CJH, A Lee, RM, CN, A Lahham, RG \\
\hline
\end{tabular}

This article is protected by copyright. All rights reserved. 


\begin{tabular}{|c|c|c|}
\hline \multirow{3}{*}{6 - Methodology } & Lead & ATB \\
\hline & Equal & $A E H, M J A, A M$ \\
\hline & Supporting & CFM \\
\hline \multirow{3}{*}{7 - Project administration } & Lead & ATB \\
\hline & Equal & NSC \\
\hline & Supporting & A Lahham, RG \\
\hline \multirow{3}{*}{8 - Resources } & Lead & ATB \\
\hline & Equal & $A E H, M J A, A M$ \\
\hline & Supporting & CFM \\
\hline \multirow{3}{*}{9 - Software } & Lead & ATB \\
\hline & Equal & $A E H, M J A, A M$ \\
\hline & Supporting & \\
\hline \multirow{3}{*}{10 - Supervision } & Lead & AEH \\
\hline & Equal & MJA, AM \\
\hline & Supporting & CFM \\
\hline \multirow{3}{*}{11 - Validation } & Lead & ATB \\
\hline & Equal & AEH, MJA, AM \\
\hline & Supporting & CFM \\
\hline \multirow{3}{*}{12 - Visualization } & Lead & ATB \\
\hline & Equal & AEH, MJA, AM \\
\hline & Supporting & CFM \\
\hline \multirow{2}{*}{$\begin{array}{l}13 \text { - Writing - original } \\
\text { draft }\end{array}$} & Lead & ATB \\
\hline & Equal & $A E H, M J A, A M$ \\
\hline
\end{tabular}

This article is protected by copyright. All rights reserved. 


\begin{tabular}{|c|c|c|}
\hline & Supporting & \\
\hline \multirow{3}{*}{$\begin{array}{l}14 \text { - Writing - review \& } \\
\text { editing }\end{array}$} & Leac & ATB \\
\hline & Equa & |AEH, MJA, AM \\
\hline & Supporting & CFM, CJH, A Lee, NSC, RM, CN, PO, A Lahham, RG \\
\hline
\end{tabular}

This article is protected by copyright. All rights reserved. 


\begin{abstract}
Background and objective: To compare the cost-effectiveness and cost-utility of home and centre-based pulmonary rehabilitation for adults with stable chronic obstructive pulmonary disease (COPD).

Methods: Prospective economic analyses were undertaken from a health system perspective alongside a randomised controlled equivalence trial in which participants referred to pulmonary rehabilitation undertook a standard 8-week outpatient centre-based or a new home-based programme. Participants underwent clinical assessment prior to programme commencement, immediately following completion and 12 months following programme completion. They provided data for utility (quality-adjusted life years [QALYs] determined using SF6D utility scores calculated from 36-Item Short Form Health Survey version 2) and effectiveness (change in distance walked on 6-minute walk test following pulmonary rehabilitation $[\Delta 6 \mathrm{MWD}])$. Individual-level cost data for the 12 months following programme completion was sourced from health care administration and government databases.
\end{abstract}

Results: Between-group mean difference point estimates for cost (-\$4497 [95\% CI \$12,250 to \$3257], utility (0.025 [-0.038 to 0.086] QALYs) and effectiveness (14 metres [11 to 39 ] $\triangle 6 \mathrm{MWD}$ ) favoured the home-based group. Cost-utility analyses demonstrated $63 \%$ of estimates falling in the dominant southeast quadrant and the probability that the new home-based model was cost-effective at a $\$ 0$ threshold for willingness to pay was $78 \%$. Results were robust to a range of sensitivity analyses. Programme completion was associated with significantly lower health care costs in the following 12 months.

This article is protected by copyright. All rights reserved. 
Conclusion: Home-based pulmonary rehabilitation provides a cost-effective alternative model for people with COPD who cannot access traditional centre-based programmes.

Clinical trial registration: NCT01423227 at clinicaltrials.gov

Key words: cost-benefit analysis; exercise therapy; health care costs; pulmonary disease, chronic obstructive; quality-adjusted life years.

Short title: Costs for pulmonary rehabilitation

\begin{abstract}
Abbreviations: CEAC, cost-effectiveness acceptability curve; COPD, chronic obstructive pulmonary disease; COTE, COPD-specific comorbidity test; ICER, incremental costeffectiveness ratios; MBS, Medicare Benefits Schedule; NE, northeast; NW, northwest; PBS, Pharmaceutical Benefits Scheme; QALY, quality-adjusted life year; RCT, randomised controlled trial; SF-36, 36-Item Short Form Health Survey version 2; SF6D, utility scores for health states; SW, southwest; SE, southeast; $\triangle 6 \mathrm{MWD}$, change in distance walked on 6-minute walk test; $\lambda$, maximum acceptable monetary value (or willingness to pay) attributed by society for a unit of health gain.
\end{abstract}

This article is protected by copyright. All rights reserved. 


\section{Introduction}

Chronic obstructive pulmonary disease (COPD) is associated with significant symptom burden for individuals, with deleterious effects on quality of life, health and functional status and substantial costs to society. ${ }^{1}$ In 2015, 2.6\% of global disability-adjusted life years were attributable to COPD. ${ }^{2}$ Pulmonary rehabilitation is a well-established treatment for people with COPD usually involving 8-12 weeks of supervised exercise and selfmanagement training in an outpatient setting. ${ }^{3}$ Benefits attributable to completion of pulmonary rehabilitation include improvements in exercise capacity, symptoms and health-related quality of life, as well as reduction in health care utilisation. ${ }^{4,5}$ International guidelines for the management of COPD unequivocally recommend referral to pulmonary rehabilitation. ${ }^{6}$

Despite its central role in COPD management, only a small minority of eligible patients worldwide complete a pulmonary rehabilitation programme. ${ }^{7}$ Identified barriers to pulmonary rehabilitation uptake and completion include limited availability of services, particularly in rural settings, and the need for frequent travel to centre-based programmes in the context of distressing dyspnoea and limited mobility. ${ }^{8}$ There have been efforts made to overcome these barriers in the past, with home-based programmes of varying design. ${ }^{9-12}$ A recent randomised controlled trial (RCT) demonstrated that a new model of structured home-based pulmonary rehabilitation had equivalent clinical outcomes and, for the first time, similar intervention costs when compared with conventional centre-based pulmonary rehabilitation. ${ }^{13}$ However, an economic evaluation would be a critical determinant of 
whether this model is suitable for clinical implementation, ${ }^{14}$ including whether programme completion gives rise to any reduction in costs following pulmonary rehabilitation.

The objective of this study was to assess the incremental impact of a new home-based model compared to centre-based practice using cost-effectiveness and cost-utility analyses. A secondary aim was to determine if pulmonary rehabilitation completion was associated with lower costs in the 12 months following the programme.

\section{Methods}

This economic evaluation was conducted alongside an equivalence RCT completed at two tertiary public hospitals in Melbourne, Australia. Institutional ethics approval was received, the trial was registered (clinicaltrials.gov, NCT01423227) and participants provided written informed consent before data collection began. The protocol, ${ }^{15}$ CONSORT statement and clinical outcomes ${ }^{13}$ have been published. These analyses and report have been prepared according to recommendations (Supplementary Table S1). ${ }^{16,17}$ In brief, 166 participants with stable $\mathrm{COPD}^{6}$ were recruited on referral to pulmonary rehabilitation and randomly assigned (1:1) to participate in home-based or centre-based programmes. Demographic variables recorded at baseline included age, sex, lung function and comorbidities.

All participants received the core pulmonary rehabilitation components of exercise training and self-management education. The home-based programme commenced with a physiotherapy home visit to establish exercise goals and supervise the first exercise session. This was followed by seven once-weekly structured telephone calls from a 
physiotherapist, using structured modules and a motivational interviewing approach. ${ }^{15}$ Centre-based participants attended an 8-week, twice weekly outpatient group-based supervised programme. ${ }^{14}$

Study measurements were repeated immediately following programme completion (end rehabilitation) and 12 months following programme completion (12-month follow-up). In line with recommendations for economic analyses, ${ }^{18}$ a multi-outcome approach was undertaken using clinical measures for both utility (primary analysis) and effectiveness (secondary analysis).

\section{Health outcomes}

Utility scores for health states (SF6D) were derived from responses to the 36-Item Short Form Health Survey version 2 (SF-36) ${ }^{19}$ using programme software (Optum, Minnesota, USA). The SF6D has been shown to be sensitive to health changes in people with COPD. ${ }^{20,21}$ The utility scores from end rehabilitation and 12-month follow-up were used for the cost-utility analysis by conversion to a quality-adjusted life year (QALY) using the 'area under the curve' approach. ${ }^{22}$

Effectiveness was reflected by change in functional exercise capacity from baseline to end rehabilitation (distance walked on 6-minute walk test, $\Delta 6 \mathrm{MWD}){ }^{23}$

\section{Resource use}

This economic evaluation took a health system perspective, which seeks to understand costs to the health system and does not include societal costs or 'out of pocket' costs for 
patients. This provides a conservative estimate of the effect as recommended for an equivalence trial. ${ }^{24}$ Costs for each participant were sourced directly including federal government-funded medical care and investigations (Medicare Benefits Schedule, MBS) and prescribed medications (Pharmaceutical Benefits Scheme, PBS), as well as state government-funded emergency department presentations, hospital admissions and outpatient appointments. A societal perspective was also sought, by collecting personal 'out-of-pocket' expenses relating to healthcare directly from participants via monthly telephone calls during the 12-month follow-up period. This enabled documentation of a comprehensive range of health care contacts outside of the hospital or medical provider databases, including community health services (Supplementary Table S2). All costs were in 2017 Australian dollars and were not discounted due to the 12-month time horizon.

\section{Statistical analysis}

Data were analysed by intention-to-treat. Participants who did not provide any clinical data after their baseline assessment were excluded from the analysis ( $\mathrm{n}=7 ; 2$ died during pulmonary rehabilitation, 3 did not attend end rehabilitation assessment and died during the follow-up period, 2 did not attend either assessment). Participants who died during the follow-up period were included in the analyses, with their total costs weighted by time and a zero value for 12-month follow-up SF6D score imputed to allow calculation of QALYs. Multiple imputation was used to address missing data, which allowed inclusion of a larger number of participants than in the clinical paper. ${ }^{13}$ Data were analysed using SPSS (v25.0, IBM, Armonk, New York, USA). The significant $\mathrm{p}$ value $(\alpha)$ was set at 0.05 .

This article is protected by copyright. All rights reserved. 
Within-group changes in clinical outcomes (QALYs, $\Delta 6 \mathrm{MWD}$ ) were assessed using linear mixed-effect models, controlling for respective baseline values, according to recommendations. ${ }^{25}$ Point estimates for mean group differences (95\% confidence intervals [CI]) were determined for QALYs and $\triangle 6 \mathrm{MWD}$ using a linear regression model controlling for group (fixed) and respective baseline values. Differences between groups for cost were analysed using bootstrapped $t$-tests (1000 samples). ${ }^{26-28}$ Multiple imputation was used to address missing data (chained equations, 25 imputations, Supplementary Table S3) for cost components (MBS, PBS), values for SF6D (end rehabilitation, 12-month follow-up) and 6MWD (end rehabilitation) (Supplementary Table S4). The final estimates were determined using Rubin’s rules. ${ }^{29}$

Results were expressed as point estimates (mean differences between groups) for incremental cost-effectiveness ratios (ICERs) for cost-utility (cost per QALY) and costeffectiveness (cost per $\Delta 6 \mathrm{MWD})$. These were presented on the cost-effectiveness plane, where the x-axis illustrates differences in utility or effect and the y-axis reflects difference in costs. ${ }^{30}$ Uncertainty around the point estimates was handled by bootstrapping; ${ }^{31}$ the succession of estimates (1000 pairs for each imputed dataset) were plotted, providing a distribution of points. The estimates were interpreted based on which of the four 'quadrants' on this plane they fall into: greater cost and greater effect (northeast, NE), greater cost and less effect (northwest, NW), lower cost and less effect (southwest, SW) or lower cost and greater effect in the desirable or 'dominant' southeast (SE) quadrant. ${ }^{22}$ The uncertainty surrounding these estimates was represented by confidence ellipses. ${ }^{30}$

This article is protected by copyright. All rights reserved. 
The 50\%, 75\% and 95\% confidence ellipses were calculated using Excel (2013, Microsoft, Redmond, WA, USA). ${ }^{32}$ When bootstrapped estimates fell into more than one quadrant on the cost-effectiveness plane, cost-effectiveness acceptability curves (CEACs) were used to represent uncertainty. ${ }^{30,33}$ The CEAC depicts the probability that the home-based programme was cost-effective relative to the centre-based programme for alternative willingness to pay (WTP) thresholds, or the maximum monetary value a society might pay for a unit of health gain $(\lambda) .{ }^{34}$ Multiple threshold values were considered as they are likely to vary widely across countries and often depend on payers' ability-to-pay. ${ }^{35}$ Provision of the intervention for both groups was costed at approximately \$300 (Supplementary Appendix S1) ${ }^{13}$ and used to indicate a threshold value for acceptability. To present the results in the context of an equivalence trial, the non-inferiority margins for clinical effectiveness (25m) $)^{36}$ and utility $(0.036)^{37}$ were applied to the cost-effectiveness plane. ${ }^{24}$ The acceptable difference in costs between the programmes was taken to be nil. As a robustness check, a generalised linear model was used to confirm the differences between groups for total health care costs. ${ }^{38}$

Multiple linear regression was used to quantify the magnitude of the effect of baseline clinical features and programme completion on total health care costs in the year following pulmonary rehabilitation.

\section{Uncertainty analysis}

Both cost-utility and cost-effectiveness analyses were repeated using a societal perspective.

This article is protected by copyright. All rights reserved. 
To test the robustness of the assumption that data were 'missing at random' as required for multiple imputation and recommended for the reference assumption, ${ }^{39}$ cost-utility was also estimated for complete cases only (no missing cost [MBS, PBS] or outcome data [SF6D]). One-way sensitivity analyses were performed using costs associated with emergency department presentations and hospital admissions, which comprise the largest proportion of health care costs, with modification of this component ( $+10 \%$ and $-10 \%)$ to assess the impact on cost-utility estimates.

Both cost-utility and cost-effectiveness analyses were repeated in the subgroup of participants with severe lung disease $(<50 \%){ }^{6}$

\section{Results}

Baseline descriptive characteristics were well matched between groups (Table 1). The home-based group did not demonstrate significantly different costs (mean difference \$4497 [95\% confidence interval -\$12,250 to \$3257]) or utility (QALYs 0.025 [-0.038 to 0.086]) compared to the centre-based group (Figure 1a, Table 1, Table 2). The costeffectiveness plane for cost-utility showed $63 \%$ of estimates fell in the 'dominant' SE quadrant, favouring the home-based model (less costly and greater utility, Supplementary Table S5). The CEAC for cost-utility showed a 78\% probability of cost-effectiveness at a WTP threshold of \$0 per QALY, rising to $81 \%$ at $\$ 50,000$ and $83 \%$ at $\$ 100,000$ (Figure

This article is protected by copyright. All rights reserved. 
1b). Thus, the probability that the home-based model would be cost effective was nearly $80 \%$, over a wide range of WTP thresholds.

The mean difference between groups also did not demonstrate significantly different clinical effect ( $\triangle 6 \mathrm{MWD} 14 \mathrm{~m}$ [-11 to 39]) for the home-based group compared to centrebased participants (Table 1). Most of the bootstrapped estimates cost-effectiveness fell into the eastern quadrants, indicating that that the home-based model was more likely to show improved effect compared to the centre-based group, as well as lower costs (66\% SE quadrant). The associated CEAC demonstrated that the probability of the home-based programme being cost-effective was $78 \%$ at a willingness-to-pay $(\kappa)$ of $\$ 0$ and $\$ 300$, rising to $86 \%$ at $\$ 50,000$ and $\$ 100,000$ per QALY.

Similar results were demonstrated in cost-utility analyses from a societal perspective (\$4316 [-\$16,328 to \$6780]). The cost-effectiveness plane demonstrated 63\% of estimates for cost-utility in the SE quadrant, again favouring the home-based model (Supplementary Table S5).

Complete case analysis showed no significant differences between groups for participant characteristics (Supplementary Table S6), costs (-\$4824 [-\$11,440 to \$1790]) or utility (QALYs 0.024 [-0.043 to 0.089]) with similar results demonstrated on the costeffectiveness plane favouring the home-based model (Supplementary Table S5). Cost-utility and cost-effectiveness results for participants with severe disease were similar to results for the full sample of participants, with a slightly higher proportion of estimates for cost-effectiveness falling in the SE quadrant, favouring the home-based model (Supplementary Table S5). 
Compared to primary analyses, sensitivity analyses varying the largest cost component (Supplementary Table S5) and analyses undertaken using non-inferiority margins demonstrated similar patterns of distribution on the cost-effectiveness plane (Supplementary Table S7).

Sensitivity analysis for health care costs using a generalised linear model supported previous results, demonstrating no significant difference $(-\$ 4497$ (-\$12,368 to $\$ 33,374)$, although the home-based group demonstrated somewhat lower costs $(\$ 15,447[\$ 15,299$ to $\$ 15,595])$ compared to the centre-based group $(\$ 19,944$ [ $\$ 19,669$ to $\$ 20,219])$ over the 12 months following completion of pulmonary rehabilitation (Table 2). The share of inpatient and emergency care costs was higher for centre-based participants, and the share for pharmaceutical costs was greater in the home-based group. There were some subtle differences demonstrated between the groups in terms of resource use, but these were not statistically significant (Table 1). As part of the societal perspective, no significant differences were observed between groups for the out-of-pocket costs associated with accessing medical care (mean difference $\$ 54$ [95\%CI -20 to 128]) or prescribed medications (mean difference \$12 [95\%CI -95 to 119]). Completion of pulmonary rehabilitation (regardless of programme location) was associated with a significant reduction in total costs in the following 12 months $(\$ 10,620$ [-\$19,572 to -\$1668]) (Table 3). Each additional metre in the baseline 6MWD was associated with a \$59 decrease [-\$94 to $-\$ 24]$ in costs, whilst more comorbidities were associated with increased costs (additional \$3549 [\$1951 to \$5146] for each point on baseline COPD- 
specific comorbidity test [COTE] index). Group assignment and other baseline scores did not contribute to this model.

\section{Discussion}

These analyses demonstrate favourable results for the new home-based model of pulmonary rehabilitation compared to centre-based practice. In situations such as this where there are no significant differences between interventions for either costs or clinical outcomes, a cost-effectiveness analysis is useful to inform decision making on resource allocation. ${ }^{40}$ The cost-effectiveness analysis demonstrated that $63 \%$ of bootstrapped point estimates found the home-based model to be 'dominant' (i.e. more effective and less costly). These results were robust using measures of both cost-utility and effectiveness in a range of scenario and sensitivity analyses. For the first time, programme completion was associated with a substantial cost saving in the following year (around \$10,000). Although infrequently used as a predictor of health care costs, the savings associated with completing pulmonary rehabilitation outweighed any cost burden associated with additional comorbidities (approximately \$3000 per point on the COTE index) providing a unique opportunity to modify potential future costs. People in the home-based group were significantly more likely to complete pulmonary rehabilitation, illustrating the potential of this model to reduce downstream health care costs. These findings have important implications for efficient allocation of limited health care resources. From a clinical perspective, each additional metre in 6MWD was significantly associated with subsequent cost reduction, further highlighting the value of this outcome for people with COPD.

This article is protected by copyright. All rights reserved. 
No previous economic analysis of pulmonary rehabilitation has compared a home-based model to a centre-based programme. Past work has been purely descriptive ${ }^{41-44}$ comparing centre-based programmes to usual care ${ }^{45-48}$ or comparing two different models of centrebased pulmonary rehabilitation (hospital versus community centre). ${ }^{49}$ Our analysis used individual-level data collected as part of a RCT, undertaken with reference to economic evaluation recommendations and reflecting a 'real life' clinical setting. As with many economic analyses, this study was powered for clinical outcomes and, in this case, to demonstrate equivalence. This may have broadened the confidence intervals ${ }^{50}$ but still permitted estimates for cost-utility and cost-effectiveness with appropriately represented uncertainty to be determined.

There were also differences between previous work ${ }^{10,51}$ and the development of this homebased model which may be responsible for the observed clinical benefits and low-cost. Participants received home-based delivery of all programme components, including exercise, education and self-management training. Telephone appointments were conducted by respiratory physiotherapists who were trained in motivational interviewing techniques and specific exercise goal setting was a critical component of every contact. ${ }^{13}$ Exercise programs were designed so that the home-based group received a similar 'dose' of exercise to the centre-based group; this was confirmed by diary entries for exercise time in the home-based group, which correlated with objective measures of physical activity. ${ }^{52}$ Participants noted the time-convenience and flexibility in training opportunities as benefits of the model. ${ }^{53}$ 
International estimates attribute the bulk of direct medical costs to hospitalisations in people with COPD. ${ }^{54}$ This pattern was also evident in the current study, with no statistically significant differences between groups for resource use. Different health care systems will be subject to variations in cost components. In a variation to the protocol, ${ }^{15}$ one-way sensitivity analyses were performed using costs associated with emergency department presentations and hospital admissions, which comprised the largest proportion of health care costs, rather than sensitivity analyses using varying assumptions about participant out-of-pocket costs as their small magnitude was unlikely to impact on the conclusions. While we were able to capture some out-of-pocket costs incurred by participants, it was not possible to gain accurate cost details relating to travel associated with health care (e.g. transport to attend appointments) or to include medications purchased 'over the counter' (i.e. not prescribed and therefore not subsidised by public insurance). It is possible that the uncertainty around these costs may have contributed to the wider confidence intervals in the societal perspective. Although these costs may only represent a small component of the overall costs with limited effect on sensitivity analysis, they could represent a substantial financial burden to an individual living with COPD. Direct non-health care costs (e.g. cost attributable to informal care) and indirect non-health care costs (e.g. days absent from paid work) were also not collected. The impact of these was unknown because the participants in this study were largely of retirement age. Nonetheless indirect costs are an important consideration for the challenge created by COPD, as it is estimated that more than half of the costs associated with COPD are in lost productivity. ${ }^{54}$ The considerable costs for people of working age with COPD makes this 
population a priority for intervention programmes and this home-based model of pulmonary rehabilitation is potentially more suitable than the conventional approach for this group.

Examination of preferences for treatment location during an exacerbation of COPD requiring inpatient care revealed that some respondents had fixed preferences for either home- or hospital-based treatment, indicating that, in the presence of clinical and cost equivalence, there should be options available. ${ }^{55}$

The magnitude of the burden of COPD provides challenges to the health care systems of all nations. Economic evaluations of new models of care need to incorporate the value of both health and non-health benefits to individuals to inform service provision and optimise healthcare resource allocation. The results from this study provide evidence for homebased pulmonary rehabilitation as an alternative for people who cannot access centre-based programme models.

\section{Data availability statement}

Requests for data sharing should be directed to A.E.H., who is the custodian of the complete set of data encompassing this study.

\section{Acknowledgements}

This study was funded by a National Health and Medical Research Council (Australia) project grant (\#1046353). A.E.H. was the recipient of an unrestricted Lung Foundation Australia / Boehringer Ingelheim COPD Research Fellowship. A.T.B. is the recipient of a

This article is protected by copyright. All rights reserved. 
Dora Lush Biomedical Postgraduate Research Scholarship (National Health and Medical Research Council, \#1115055).

\section{Disclosure statement:}

C.F.MD has directed speaker's fees from Menarini and Astra Zeneca to her institution (unrelated work). M.J.A. holds investigator initiated grants for unrelated research from Pfizer and Boehringer-Ingelheim. He has also undertaken an unrelated consultancy for Sanofi.

\section{Author contributions:}

This article is protected by copyright. All rights reserved. 


\section{References}

1. Miravitlles M, Ribera A. Understanding the impact of symptoms on the burden of COPD. Respir Res. 2017;18:67.

2. Global Burden of Disease 2015 Chronic Respiratory Disease Collaborators. Global, regional, and national deaths, prevalence, disability-adjusted life years, and years lived with disability for chronic obstructive pulmonary disease and asthma, 1990-2015: a systematic analysis for the Global Burden of Disease Study 2015. Lancet Respir Med. 2017;5:691-706.

3. Spruit M, Pitta F, Garvey C, ZuWallack R, Roberts C, Collins E, Goldstein R, McNamara R, Surpas P, Atsuyoshi K, Lopez-Campos J, Vogiatzis I, Williams J, Lareau S, Brooks D, Troosters T, Singh S, Hartl S, Clini E, Wouters E. Differences in content and organisational aspects of pulmonary rehabilitation programmes. Eur Respir J. 2014;43:1326-37.

4. McCarthy B, Casey D, Devane D, Murphy K, Murphy E, Lacasse Y. Pulmonary rehabilitation for chronic obstructive pulmonary disease. Cochrane Database Syst Rev. 2015;2:CD003793.

5. Puhan M, Gimeno-Santos E, Cates C, Troosters T. Pulmonary rehabilitation following exacerbations of chronic obstructive pulmonary disease. Cochrane Database Syst Rev. 2016;10:CD005305.

6. From the Global Strategy for the Diagnosis, Management and Prevention of COPD, Global Initiative for Chronic Obstructive Lung Disease (GOLD); 2017. Accessed at http://goldcopd.org on June 19, 2017.

This article is protected by copyright. All rights reserved. 
7. Desveaux L, Janaudis-Ferreira T, Goldstein R, Brooks D. An international comparison of pulmonary rehabilitation: a systematic review. COPD. 2015;12:144-53.

8. Keating A, Lee A, Holland A. What prevents people with chronic obstructive pulmonary disease from attending pulmonary rehabilitation? A systematic review. Chron Respir Dis. 2011;8:89-99.

9. Guell M, Lucas P, Galdiz J, Montemayor T, Gonzalez-Moro J, Gorostiza A, Ortega F, Bellon J, Guyatt G. Home vs hospital-based pulmonary rehabilitation for patients with chronic obstructive pulmonary disease: a Spanish multicenter trial. Arch Bronconeumol. 2008;44:512-8.

10. Maltais F, Bourbeau J, Shapiro S, Lacasse Y, Perrault H, Baltzan M, Hernandez P, Rouleau M, Julien M, Parenteau S, Paradis B, Levy RD, Camp P, Lecours R, Audet R, Hutton B, Penrod JR, Picard D, Bernard S; Chronic Obstructive Pulmonary Disease Axis of Respiratory Health Network, Fonds de recherche en santé du Québec. Effects of home-based pulmonary rehabilitation in patients with chronic obstructive pulmonary disease: a randomized trial. Ann Intern Med. 2008;149:869-78.

11. Puente-Maestu L, Sanz M, Sanz P, Cubillo J, Mayol J, Casaburi R. Comparison of effects of supervised versus self-monitored training programmes in patients with chronic obstructive pulmonary disease. Eur Respir J. 2000;15:517-25.

12. Horton E, Mitchell K, Johnson-Warrington V, Apps L, Sewell L, Morgan M, Taylor R, Singh S. Comparison of a structured home-based rehabilitation programme with conventional supervised pulmonary rehabilitation: a randomised non-inferiority trial. Thorax. 2017;73:29-36.

This article is protected by copyright. All rights reserved. 
13. Holland A, Mahal A, Hill C, Lee A, Burge A, Cox N, Moore R, Nicolson C. Home-based rehabilitation for COPD using minimal resources: a randomised, controlled equivalence trial. Thorax. 2017;72:57-65.

14. Spruit M, Singh S, Garvey C, ZuWallack R, Nici L, Rochester C, Hill K, Holland A. An official American Thoracic Society/European Respiratory Society statement: key concepts and advances in pulmonary rehabilitation. Am J Respir Crit Care Med. 2013;188:e13-64.

15. Holland A, Mahal A, Hill C, Lee A, Burge A, Moore R, Nicolson C, O'Halloran P. Benefits and costs of home-based pulmonary rehabilitation in chronic obstructive pulmonary disease - a multi-centre randomised controlled equivalence trial. BMC Pulm Med. 2013;13:57.

16. Ramsey S, Willke R, Glick H. Cost-effectiveness analysis alongside clinical trials II - an ISPOR good research practices task force report. Value Health. 2015;18:161-72. 17. Husereau D, Drummond M, Petrou S, Carswell C, Moher D, Greenberg D, Augustovski F, Briggs A. Consolidated Health Economic Evaluation Reporting Standards (CHEERS) - explanation and elaboration: a report of the ISPOR health economic evaluation publication guidelines good reporting practices task force. Value Health. 2013;16:231-50.

18. Cazzola M, Macnee W, Martinez F, Rabe K, Franciosi L, Barnes P, Brusasco V, Burge P. Outcomes for COPD pharmacological trials: from lung function to biomarkers. Eur Respir J. 2008;31:416-69.

This article is protected by copyright. All rights reserved. 
19. Brazier J, Rowen D, Hanmer J. Revised SF-6D scoring programmes: a summary of improvements. Revised SF-6D scoring programmes: a summary of improvements 2008;40:14-15.

20. Harper R, Brazier J, Waterhouse J, Walters S, Jones N, Howard P. Comparison of outcome measures for patients with chronic obstructive pulmonary disease (COPD) in an outpatient setting. Thorax. 1997;52:879-97.

21. Mahler D, Mackowiak J. Evaluation of the Short-Form 36-Item questionnaire to measure health-related quality of life in patient with COPD. Chest. 1995;107:1585-9.

22. Drummond M, Sculpher M, Claxton K, Stoddart G, Torrance G. Methods for the economic evaluation of health care programmes. 4th ed. Oxford: Oxford University Press; 2015.

23. Holland A, Spruit M, Troosters T, Puhan M, Pepin V, Saey D, McCormack M, Carlin B. An official European Respiratory Society/American Thoracic Society technical standard: field walking tests in chronic respiratory disease. Eur Respir J. 2014;44:1428-46.

24. Bosmans J, de Bruijne M, van Hout H, Hermens M, Ader H, van Tulder M.

Practical guidelines for economic evaluations alongside equivalence trials. Value Health. 2008;11:251-8.

25. de Livera A, Zaloumis S, Simpson J. Models for the analysis of repeated continuous outcome measures in clinical trials. Respirology. 2014;19:155-61.

26. Mihaylova B, Briggs A, O’Hagan A, Thompson S. Review of statistical methods for analysing healthcare resources and costs. Health Econ. 2011;20:897-916.

This article is protected by copyright. All rights reserved. 
27. Thompson S, Barber J. How should cost data in pragmatic randomised trials be analysed? BMJ. 2000;320:1197-200.

28. Briggs A, Gray A. The distribution of health care costs and their statistical analysis for economic evaluation. J Health Serv Res Policy. 1998;3:233-45.

29. Rubins D. Multiple imputation for nonresponse in surveys. New York: John Wiley 1987.

30. Briggs A, Fenn P. Confidence intervals or surfaces? Uncertainty on the costeffectiveness plane. Health Econ. 1998;7:723-40.

31. Briggs A, Wonderling D, Mooney C. Pulling cost-effectiveness up by its bootstraps: a non-parametric approach to confidence interval estimation. Health Econ. 1997;6:327-40.

32. Nixon R, Wonderling D, Grieve R. Non-parametric methods for cost-effectiveness analysis: the central limit theorem and the bootstrap compared. Health Econ. 2010;19:31633.

33. van Hout B, Al M, Gordon G, Rutten F. Costs, effects and C/E ratios alongside a clinical trial. Health Econ. 1994;3:309-19.

34. Fenwick E, O'Brien B, Briggs A. Cost-effectiveness acceptability curves - facts, fallacies and frequently asked questions. Health Econ. 2004;13:405-15.

35. Shiroiwa T, Sung Y, Fukuda T, Lang H, Bae S, Tsutani K. International survey on willingness-to-pay (WTP) for one additional QALY gained: what is the threshold of cost effectiveness? . Health Econ. 2010:422-37.

This article is protected by copyright. All rights reserved. 
36. Holland A, Hill C, Rasekaba T, Lee A, Naughton M, McDonald C. Updating the minimal important difference for six-minute walk distance in patients with chronic obstructive pulmonary disease. Arch Phys Med Rehabil. 2010;91:221-5.

37. Walters S, Brazier J. Comparison of the minimally important difference for two health state utility measures: EQ-5D and SF-6D. Qual Life Res. 2005;14:1523-32.

38. Barber J, Thompson S. Multiple regression of cost data: use of generalised linear models. J Health Serv Res Policy. 2004;9:197-204.

39. Gabrio A, Mason A, Baio G. Handling missing data in within-trial costeffectiveness analysis: a review with future recommendations. PharmacoEconom Open 2017;1:79-97.

40. Dakin H, Wordsworth S. Cost-minimisation analysis versus cost-effectiveness analysis, revisted. Health Econ. 2013;22:22-34.

41. California Pulmonary Rehabilitation Collaborative Group. Effects of pulmonary rehabilitation on dyspnoea, quality of life and healthcare costs in California. J Cardiopulm Rehabil. 2004;24:52-62.

42. Chakravorty I, Fasakin C, Paine T, Narasimhaiah D, Austin G. Outpatient-based pulmonary rehabilitation for COPD: a cost of illness study. ISRN Pulmonology 2011;364989.

43. Golmohammadi K, Jacobs P, Sin D. Economic evaluation of a community-based pulmonary rehabilitation program for chronic obstructive pulmonary disease. Lung. 2004;182:187-96.

This article is protected by copyright. All rights reserved. 
44. Reina-Rosenbaum R, Bach J, Penek J. The cost/benefits of pulmonary rehabilitation. Arch Phys Med Rehabil. 1997;78:240-4.

45. Farias C, Resqueti V, Dias F, Borghi-Silva A, Arena R, Fregonezi G. Costs and benefits of pulmonary rehabilitation in chronic obstructive pulmonary disease: a randomized controlled trial. Rev Bras Fisioter. 2014;18:165-73.

46. Gillespie P, O'Shea E, Casey D, Murphy K, Devance D, Cooney A, Mee L, Kirwan C. The cost-effectiveness of a structured education pulmonary rehabilitation programme for chronic obstructive pulmonary disease in primary care: the PRINCE cluster randomised trial. BMJ Open 2013;3:e003479.

47. Griffiths T, Phillips C, Davies S, Burr M, Campbell I. Cost effectiveness of an outpatient multidisciplinary pulmonary rehabilitation programme. Thorax. 2001;56:77984.

48. Hoogendoorn M, van Wetering C, Schols A, Rutten-van Molken M. Is INTERdisciplinary COMmunity-based COPD management (INTERCOM) cost-effective. Eur Respir J. 2010;35:79-97.

49. Waterhouse J, Walters S, Oluboyede Y, Lawson R. A randomised 2x2 trial of community versus hospital pulmonary rehabilitation, followed by telephone or conventional follow-up. Health Technol Assess. 2010;14:1-140.

50. Briggs A. Economic evaluation and clinical trials: size matters. BMJ. 2000;321:1362-3.

51. Strijbos JH PD, van Alterna R, Gimeno F, Koeter GH. A comparison between an outpatient hospital-based pulmonary rehabilitation program and a home-case pulmonary 
rehabilitation program in patients with COPD: a follow-up of 18 months. Chest. 1996;109:366-72.

52. Lahham A, McDonald C, Mahal A, Lee A, Hill C, Burge A, Cox N, Moore R, Nicolson C, O'Halloran P, Gillies R, Holland A. Acceptability and validity of a home exercise diary used in home-based pulmonary rehabilitation: a secondary analysis of a randomised controlled trial. Clin Respir J. 2018;12:2057-64.

53. Lahham A, McDonald C, Mahal A, Lee A, Hill C, Burge A, Cox N, Moore R, Nicolson C, O'Halloran P, Gillies R, Holland A. Home-based pulmonary rehabilitation for people with COPD: a qualitative study reporting the patient perspective. Chron Respir Dis. 2018;15:123-30.

54. European Respiratory Society. Chapter 2. The economic burden of lung disease. European Respiratory Society; 2016. Accessed at http://www.erswhitebook.org/chapters/the-economic-burden-of-lung-disease/ on June 19, 2017.

55. Utens C, Goossens L, van Schayck O, Rutten-van Molken M, van Litsenburg W, Janssen A, van der Pouw A, Smeenk F. Patient preference and satisfaction in hospital-athome and usual hospital care for COPD exacerbations: results of a randomised controlled trial. Int J Nurs Stud. 2013;50:1537-49.

This article is protected by copyright. All rights reserved. 
Table 1 Descriptive characteristics of 159 study participants by group

\begin{tabular}{|c|c|c|}
\hline Participant characteristic & Centre-based $(n=82)$ & Home-based $(\mathrm{n}=77)$ \\
\hline Age (years), mean \pm SD & $69 \pm 9$ & $71 \pm 9$ \\
\hline Female, n (\%) & $50(61)$ & $46(60)$ \\
\hline $\mathrm{FEV}_{1}$ (\%predicted), mean $\pm \mathrm{SD}$ & $49 \pm 20$ & $53 \pm 18$ \\
\hline COTE index (score), median & $0.5[0,2]$ & $0[0,2]$ \\
\hline \multicolumn{3}{|l|}{ [IQR] } \\
\hline \multicolumn{3}{|l|}{ 6MWD (metres), mean (95\% CI) } \\
\hline Baseline & 413 (389 to 437$)$ & 399 (372 to 426$)$ \\
\hline End rehabilitation & 424 (414 to 433$)$ & 423 (415 to 432$)$ \\
\hline$\triangle 6 \mathrm{MWD}$ & 11 (3 to 19$)$ & 24 (18 to 31$)$ \\
\hline \multicolumn{3}{|l|}{ SF6D (score), mean (95\% CI) } \\
\hline Baseline & $0.642(0.620$ to 0.665$)$ & $0.638(0.611$ to 0.664$)$ \\
\hline End rehabilitation & $0.643(0.405$ to 0.882$)$ & $0.671(0.429$ to 0.912$)$ \\
\hline 12-month follow-up & 0.597 (0.318 to 0.876$)$ & $0.620(0.326$ to 0.913$)$ \\
\hline QALY & $0.621(0.390$ to 0.851$)$ & $0.645(0.392$ to 0.898$)$ \\
\hline \multicolumn{3}{|c|}{ Admissions over 12-month follow up, n (\%) } \\
\hline 0 admissions & $45(55)$ & $47(61)$ \\
\hline 1 admission & $11(13)$ & $11(14)$ \\
\hline 2-5 admissions & $19(23)$ & $16(21)$ \\
\hline 6-10 admissions & $7(9)$ & $3(4)$ \\
\hline
\end{tabular}

This article is protected by copyright. All rights reserved. 
$46 \mathrm{MWD}$, change in 6MWD from baseline to end rehabilitation; COTE, chronic obstructive pulmonary disease-specific comorbidity index; $\mathrm{FEV}_{1}$, forced expiratory volume in 1 second; SF6D, utility score derived from Medical Outcomes Survey Short Form 36-item questionnaire; 6MWD, distance walked on 6-minute walk test; QALY, quality-adjusted life year derived from SF6D at end rehabilitation and 12-month followup.

This article is protected by copyright. All rights reserved. 
This article is protected by copyright. All rights reserved. 
Table 2 Health care costs for 12 months following completion of pulmonary rehabilitation

\begin{tabular}{|c|c|c|c|}
\hline Health care cost (\$) & Home-based & Centre-based & $\begin{array}{c}\text { Between-group difference } \\
\text { (centre minus home) }\end{array}$ \\
\hline Total & $15,447(15,299$ to 15,595$)$ & $19,944(19,669$ to 20,219$)$ & $-4497(-12,250$ to 3257$)$ \\
\hline \multicolumn{4}{|l|}{ Main components } \\
\hline Medicare Benefits Schedule & 2635 (2485 to 2784$)$ & 2957 (2763 to 3152) & $-323(-1174$ to 528$)$ \\
\hline Pharmaceutical Benefits Scheme & 3428 (3160 to 3696$)$ & 2997 (2607 to 3386) & 431 (-999 to 1861$)$ \\
\hline $\begin{array}{l}\text { Hospital admissions, emergency } \\
\text { department, ambulance }\end{array}$ & 8804 (8721 to 8888$)$ & $13,042(12,932$ to 13,153$)$ & $-4238(-7854$ to 622$)$ \\
\hline
\end{tabular}

Data are presented as mean (95\% CI) 12-month health care costs for each group; mean difference (95\% CI) between groups; \$, AUD 2017. 
Table 3 Multiple linear regression for total costs over 12 months following completion of pulmonary rehabilitation

\begin{tabular}{|c|c|c|c|c|c|c|}
\hline \multirow[t]{2}{*}{ Variables } & \multicolumn{2}{|c|}{ Unstandardised coefficient } & \multicolumn{2}{|c|}{$95 \%$ CI for B } & \multirow{2}{*}{$\mathrm{t}$} & \multirow{2}{*}{$\mathrm{p}$} \\
\hline & $\mathrm{B}$ & Standard error & Lower bound & Upper bound & & \\
\hline Constant & $\$ 44,169$ & $\$ 8393$ & $\$ 2827,720$ & $\$ 60,619$ & 5.263 & $<0.001$ \\
\hline Pulmonary rehabilitation completion (yes/no) & $-\$ 10,620$ & $\$ 4567$ & $-\$ 19,572$ & $-\$ 1668$ & -2.325 & 0.020 \\
\hline Baseline 6MWD (metres) & $-\$ 59$ & $\$ 18$ & $-\$ 94$ & $-\$ 24$ & -3.279 & 0.001 \\
\hline COTE index (score) & $\$ 3549$ & $\$ 815$ & $\$ 1951$ & $\$ 5146$ & 4.354 & $<0.001$ \\
\hline
\end{tabular}

COTE, chronic obstructive pulmonary disease-specific comorbidity index; 6MWD, distance walked on 6-minute walk test; \$, AUD 2017; p<0.05. 
$\$ 30,000$

$\$ 20,000$

$---95 \%$

- $-75 \%$

$-50 \%$

- Point estimate

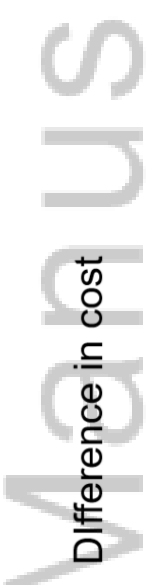

$-\$ 10,000$

$\$ 10,000$

政

(1) $\$ 0$

$\$ 0$

$-\$ 20,000$

$-\$ 30,000$

$-0.150$

$-0.100$

$-0.050$

0.000

0.050

0.100

0.150

Difference in utility

RESP_13667_Fig1a.tif 


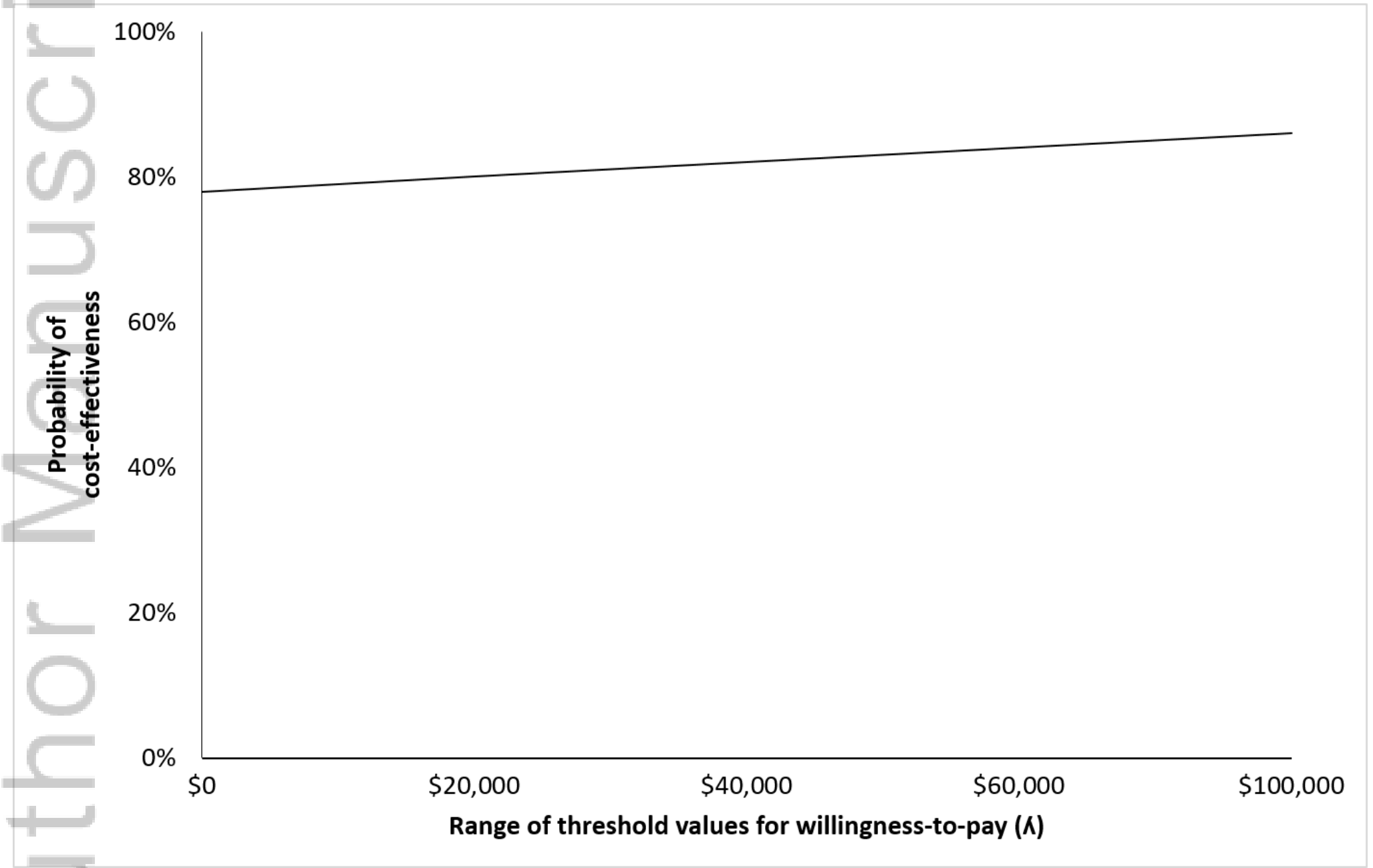

RESP_13667_Fig1b.tif

This article is protected by copyright. All rights reserved. 


\section{University Library}

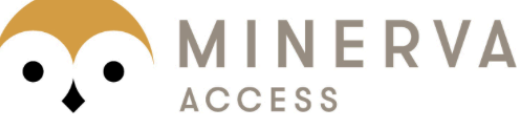

A gateway to Melbourne's research publications

Minerva Access is the Institutional Repository of The University of Melbourne

Author/s:

Burge, AT;Holland, AE;McDonald, CF;Abramson, MJ;Hill, CJ;Lee, AL;Cox, NS;Moore,

R;Nicolson, C;O'Halloran, P;Lahham, A;Gillies, R;Mahal, A

Title:

Home-based pulmonary rehabilitation for COPD using minimal resources: An economic analysis

Date:

2019-08-16

Citation:

Burge, A. T., Holland, A. E., McDonald, C. F., Abramson, M. J., Hill, C. J., Lee, A. L., Cox, N. S., Moore, R., Nicolson, C., O'Halloran, P., Lahham, A., Gillies, R. \& Mahal, A. (2019). Homebased pulmonary rehabilitation for COPD using minimal resources: An economic analysis. RESPIROLOGY, 25 (2), pp.183-190. https://doi.org/10.1111/resp. 13667.

Persistent Link:

http://hdl.handle.net/11343/286310 